\title{
Helicobacter pylori infection and vitamin B-12 deficiency- A cross sectional study
}

\author{
Ravi K1, Jacob Joseph², David Mathew Thomas² \\ ${ }^{1}$ Professor and Head, ${ }^{2} J u n i o r$ Resident, Department Internal Medicine, Bangalore Medical College and Research \\ Institute (BMCRI), Bengaluru, Karnataka, India
}

Background: Vitamin $B_{12}$ deficiency is a common, often overlooked medical problem in adult population. Diagnosis of vitamin $B_{12}$ deficiency is incomplete without the evaluation of underlying cause. In majority of the cases Vitamin $\mathrm{B}_{12}$ deficiency is attributed to malnutrition. $\mathrm{H}$. pylori infection plays an important role in the development of atrophic gastritis and related malabsorption. Hence it is suggested that there may be a relationship between $h$. pylori infection and vitamin $B_{12}$ deficiency. Aims and Objective: To evaluate correlation of helicobacter pylori infection and blood levels of vitamin $B_{12}$. Materials and Methods: A total of 120 patients with deficient serum vitamin $B_{12}$ levels were evaluated. Upper $\mathrm{G}$ I Endoscopy was performed and gastric biopsies were obtained for Histopathological examination and histological evidence of $\mathrm{H}$. pylori infection. Results: Tissue biopsy revealed chronic atrophic gastritis in 65 patients and chronic antral gastritis in 39 patients. H. pylori infection by histology was positive in 68 patients. There was significant correlation between atrophic gastritis and $\mathrm{H}$. pylori as well as between $\mathrm{H}$. pylori and $\mathrm{B}_{12}$ deficiency. Conclusion: $\mathrm{H}$. pylori has an effect on gastric mucosa, which influences the absorption of vitamin $B_{12}$. Thus individuals with $B_{12}$ deficiency must be subjected for diagnostic evaluation of H.pylori infection and appropriate therapy must be initiated.

Key words: H.pylori, Vit- $\mathrm{B}_{12}$ deficiency, Chronic gastritis

Access this article online

Website:

http://nepjol.info/index.php/AJMS

DOI: 10.3126/ajms.v8i4.17280

E-ISSN: 2091-0576

P-ISSN: 2467-9100

\section{INTRODUCTION}

Vitamin $\mathrm{B}_{12}$ deficiency is a common but often underrecognized disorder. It has a prevalence ranging from $3 \%$ to $40 \%$ in adult population. ${ }^{1}$ It has a wide spectrum of manifestations that range from asymptomatic to hematologic, neuropsychiatric, and developmental complications. ${ }^{1}$ Release of cobalamin from food requires acid and pepsin. This forms a stable complex with gastric $\mathrm{R}$ binder which is taken up by intrinsic factor for absorption. ${ }^{2}$ Food-cobalamin malabsorption is marked by the inability to release cobalamin from food which can be traced to gastric defects. However other mechanisms may also play a role. ${ }^{2}$

By far, $\mathrm{H}$. pylori infection is one of the most common infection worldwide. ${ }^{3}$ It is estimated that more than half of the adult population in developed countries and $90 \%$ of those in developing countries is infected with this bacterium. Although the vast majority of infected individuals are asymptomatic, it is well known that $\mathrm{H}$. pylori is involved in gastritis, gastric and duodenal ulcers, gastric adenocarcinoma and mucosa-associated lymphoid tissue lymphoma. ${ }^{3}$ Numerous studies suggest that $H$. pylori infection is highly associated with atrophic gastritis. ${ }^{3}$

Atrophic gastritis is a histopathologic entity characterized by chronic inflammation of gastric mucosa with loss of gastric glandular cells and its replacement by intestinal-type epithelium, pyloric-type glands, and fibrous tissue. The two main causes for atrophic gastritis are H. pylori associated gastritis and autoimmune gastritis. ${ }^{4} \mathrm{H}$. pylori infection most often presents as predominantly antral gastritis with normal or increased acid production. When inflammation remains limited to the antrum, increased acid production results in greater risk of duodenal peptic ulcer. In other patients gastritis may progress to involve the body and fundus of 
stomach producing multifocal atrophic gastritis. ${ }^{5}$ There is evidence to suggest that chronic H.pylori gastritis may be a frequent cause of cobalamin deficiency, especially in developing countries. ${ }^{6}$

The present study was undertaken to evaluate patients with cobalamin deficiency and its association with $\mathrm{H}$. pylori infection. In addition, any relationship between the presence of cobalamin deficiency and demographic, hematologic and histopathologic parameters were also evaluated.

\section{MATERIALS AND METHODS}

The study was done in the Department of General Medicine, Bangalore Medical College and Research Institute, from January 2012 to January 2014. A total of 120 patients attending outpatient department and patients admitted, with a serum vitamin $B_{12}$ level less than $200 \mathrm{pg} / \mathrm{ml}$ were included in the study. All patients were aged 18 years or more.

Patients with postgastrectomy status, renal or hepatic failure, pregnant ladies and patients who had received prior H. pylori eradication therapy were excluded from the study. It also excluded immunocompromised states like HIV infection, diabetes mellitus due to multiple factors involved in these conditions.

Patients who had agreed to participate and given informed written consent were included in the study. Detailed evaluation including demographic profile, clinical examination, co-morbid conditions and drug intake analysis were done in all patients.

Complete hemogram, including peripheral smear was done for all patients. Also upper gastrointestinal endoscopy was performed in all patients to study the macroscopic appearances of gastric mucosa and to obtain biopsy specimens from gastric antrum, body and fundus. Specimens were collected by separate sterile forceps from each site. Biopsy samples were sent for processing and histopathologic examination, including staining for H. pylori.

\section{Statistical methods}

The SPSS version 22 was used for statistical analysis. Results on continuous measurements are presented on Mean \pm SD and results on categorical measurements are presented in Number (\%).Chi-square/Fisher Exact test has been used to find the significance of study parameters on categorical scale between two or more groups. Independent sample t-test and ANOVA were used in analysis of mean differences of two groups. For statistical significance $\mathrm{p}$ value $<0.05$ was accepted as significant.

\section{RESULTS}

In our study we collected a total of 120 patients with proven vitamin $\mathrm{B}_{12}$ deficiency. The mean age of the patients was $53.75 \pm 19.64$ yrs with 61 males $(50.8 \%)$ and 59 females $(49.1 \%)$. There was no history of chronic intake of any drug among the subjects. Forty-two of them were alcoholic, 12 had hypertension and 8 of them were diabetics. Fatiguability was the predominant symptom (92\%) followed by loss of appetite, nausea and vomiting. Interestingly $72(60 \%)$ of them had fever that subsided with cobalamin injection alone. Chronic epigastric pain and dyspepsia was observed in 66 patients (55\%). On examination, pigmentation (like knuckle pigmentation) and icterus were observed in 78 subjects. Fourteen patients had features of subacute combined degeneration.

Mean hemoglobin was $5.49 \pm 1.36 \mathrm{gm} \%$ with maximum in the $5-7 \mathrm{~g} / \mathrm{dl}$ group (55.8\%). Improvement in hemoglobin was seen with cobalamin and iron supplementation. Mean MCV was $100.63 \pm 5.97$ and majority had MCV more than 100. Mean serum vitamin $B_{12}$ level was $98.74 \pm 30.01 \mathrm{pg} / \mathrm{ml}$, with $50 \%$ patients having levels less than $100 \mathrm{pg} / \mathrm{ml}$. On endoscopy, normal appearing mucosa was found in 32 subjects but biopsy showed features of atrophic gastritis in 28 of these patients. On Histopathologic evaluation 54\% patients had chronic atrophic gastritis. Normal histology was noted in 5\% subjects (Table 1). Fifty-eight subjects were positive for Helicobacter pylori (56.6\%) (Table 2).

Distribution of Vitamin $B_{12}$ in relation to $H$. pylori status showed that there is significant relationship between the $\mathrm{B}_{12}$ value and the $\mathrm{H}$. pylori status. More than $60 \%$ of $\mathrm{H}$. pylori negative cases had serum $\mathrm{B}_{12}$ value greater than 100, whereas among those patients with positive H. pylori status, majority $(58 \%)$ had vitamin $\mathrm{B}_{12}$ value less than 100 (Table 3).

Hence a low value of vitamin $\mathrm{B}_{12}$, especially less than 100 , is an indicator of $\mathrm{H}$. pylori infection. Significant relationship was observed between vitamin $B_{12}$ and $\mathrm{H}$. pylori status using independent sample t-test. Here the

\begin{tabular}{lc}
$\begin{array}{l}\text { Table 1: Distribution of biopsy findings among } \\
\text { patients studied }\end{array}$ \\
\hline Endoscopic findings & Frequency (\%) \\
\hline Chronic atrophic gastritis & $65(54.17)$ \\
Chronic antral gastritis & $39(32.50)$ \\
Peptic ulcer & $9(7.50)$ \\
Normal & $7(5.83)$ \\
Total & $120(100.0)$ \\
\hline
\end{tabular}


observed values of vitamin $\mathrm{B}_{12}$ are compared between two groups. There has been a significant difference in the vitamin $\mathrm{B}_{12}$ values among the two $\mathrm{H}$. pylori groups $(\mathrm{t}=3.01$, $\mathrm{df}=118, \mathrm{p}$ value $=0.003)$. The average value of vitamin $\mathrm{B}_{12}$ for the group with $\mathrm{H}$-pylori negative biopsy status was $108.87 \pm 4.08$ but that of other group with H- Pylori positive biopsy status is $91.76 \pm 3.49$. Hence the group with $\mathrm{H}$-pylori infection is observed to have a significant less vitamin $B_{12}$ value compared to the other group (Table 4).

Similarly distribution of Biopsy findings in relation to H. pylori status using Fisher's exact test showed that there is significant relationship between the endoscopic findings and the H. pylori Status. Almost $73 \%$ of patients who are categorized as chronic atrophic gastritis has shown positive H. pylori Status. Also majority of chronic antral gastritis cases showed positivity for H. pylori. In patients who are negative to $H$. pylori other two endoscopic findings are observed ('Table 5).

The relationship between the $\mathrm{B}_{12}$ values and the endoscopic findings is checked using ANOVA procedure showed

\section{Table 2: H. Pylori status among patients studied}

\begin{tabular}{lc} 
H. Pylori status & Frequency (\%) \\
\hline Negative & $52(43.33)$ \\
Positive & $68(56.67)$ \\
Total & $120(100.0)$ \\
\hline
\end{tabular}

no significant relationship between these variables (p-value 0.511).

\section{DISCUSSION}

Vitamin $\mathrm{B}_{12}$ deficiency is the most common cause of megaloblastic anaemia and it also may cause neurological problems. ${ }^{7}$ The determination of serum vitamin $B_{12}$ levels is the standard test used for diagnosing vitamin $\mathrm{B}_{12}$ deficiency. It is necessary to establish the cause for this deficiency, as it can be associated with inadequate dietary intake, disorders of ilium- causing decreased absorption, disorders related to secretion of gastric pepsin, and intrinsic factor from parietal cells. ${ }^{8}$

Helicobacter pylori has been demonstrated as an etiologic agent in vitamin $\mathrm{B}_{12}$ deficiency, either by using specific absorption test or by evaluating the effect of H.pylori eradication treatment on serum vitamin $B_{12}$ level. In population with high prevalence of $\mathrm{H}$. pylori infection, the frequency of vitamin $\mathrm{B}_{12}$ deficiency and its clinical consequences is expected to be high. $\mathrm{H}$. pylori can cause $\mathrm{B}_{12}$ malabsorption by hypochlorhydria associated with atrophic gastritis. Hypochlorhydria may lead to a failure in the splitting of $\mathrm{B}_{12}$ from food binders and its subsequent transfer to salivary R-binder in the stomach. ${ }^{9}$

Table 3: Distribution of $\mathrm{B}_{12}$ in relation to $\mathrm{H}$. pylori status [Count, row \%, column \%]

\begin{tabular}{lccccc} 
H. Pylori status & \multicolumn{3}{c}{$\mathbf{B}_{\mathbf{1 2}}$ level } & Total & p value \\
\cline { 2 - 4 } & Less than $\mathbf{1 0 0}$ & Between $\mathbf{1 0 0}$ and $\mathbf{1 5 0}$ & Greater than $\mathbf{1 5 0}$ & \\
\hline Negative & 20.00 & 30.00 & 2.00 & 52.00 & 0.035 \\
& $38.46 \%$ & $57.69 \%$ & $3.85 \%$ & $100.00 \%$ & $43.33 \%$ \\
Positive & $33.33 \%$ & $51.72 \%$ & $100.00 \%$ & 6.00 & $100.00 \%$ \\
& 40.00 & 28.00 & $0.00 \%$ & $56.67 \%$ & 120.00 \\
Total & $58.82 \%$ & $41.18 \%$ & $0.00 \%$ & $100.00 \%$ & $100.00 \%$ \\
\end{tabular}

Fisher's Exact test : $\mathrm{X}^{2}=6.72, \mathrm{df}=2, \mathrm{p}$ value $=0.035$

Table 4: Distribution of endoscopic findings in relation to $\mathrm{H}$. pylori status [Count, row \%, column \%]

\begin{tabular}{|c|c|c|c|c|c|c|}
\hline \multirow[t]{2}{*}{ H. Pylori status } & \multicolumn{5}{|c|}{ Endoscopic findings } & \multirow[t]{2}{*}{$p$ value } \\
\hline & Chronic atrophic gastritis & Chronic antral gastritis & Peptic ulcer & Normal & Total & \\
\hline \multirow[t]{3}{*}{ Negative } & 18.00 & 18.00 & 9.00 & 7.00 & 52.00 & $<0.0001$ \\
\hline & $34.62 \%$ & $34.62 \%$ & $17.31 \%$ & $13.46 \%$ & $100.00 \%$ & \\
\hline & $27.69 \%$ & $46.15 \%$ & $100.00 \%$ & $100.00 \%$ & $43.33 \%$ & \\
\hline \multirow[t]{3}{*}{ Positive } & 47.00 & 21.00 & 0.00 & 0.00 & 68.00 & \\
\hline & $69.12 \%$ & $30.88 \%$ & $0.00 \%$ & $0.00 \%$ & $100.00 \%$ & \\
\hline & $72.31 \%$ & $53.85 \%$ & $0.00 \%$ & $0.00 \%$ & $56.67 \%$ & \\
\hline \multirow[t]{3}{*}{ Total } & 65.00 & 39.00 & 9.00 & 7.00 & 120.00 & \\
\hline & $54.17 \%$ & $32.50 \%$ & $7.50 \%$ & $5.83 \%$ & $100.00 \%$ & \\
\hline & $100.00 \%$ & $100.00 \%$ & $100.00 \%$ & $100.00 \%$ & $100.00 \%$ & \\
\hline
\end{tabular}




\begin{tabular}{|c|c|c|c|c|c|}
\hline \multirow[t]{2}{*}{ Parameters } & \multicolumn{4}{|c|}{ HPE finding } & \multirow[t]{2}{*}{$p$ value } \\
\hline & Chronic atrophic gastritis & Chronic antral gastritis & Peptic ulcer & Normal & \\
\hline Age (years) & $52.31 \pm 19.32$ & $58.26 \pm 19.98$ & $55.67 \pm 20.20$ & $43.00 \pm 17.44$ & $>0.05$ \\
\hline MCV & $100.48 \pm 6.35$ & $100.72 \pm 5.7$ & $102.67 \pm 5.02$ & $99.00 \pm 5.2$ & $>0.05$ \\
\hline $\mathrm{B}_{12}$ & $96.65 \pm 30.71$ & $97.90 \pm 28.59$ & $109.33 \pm 36.61$ & $109.29 \pm 22.06$ & $>0.05$ \\
\hline H. pylori & $69.12 \%$ & $30.88 \%$ & $0.00 \%$ & $0.00 \%$ & $<0.05$ \\
\hline $\mathrm{Hb}$ & $5.52 \pm 1.28$ & $5.39 \pm 1.52$ & $5.58 \pm 1.71$ & $5.57 \pm 0.93$ & $>0.05$ \\
\hline
\end{tabular}

Chronic carrier state is very common in H.pylori infection and if left untreated $\mathrm{H}$. pylori infection may become life long. ${ }^{10}$ Patients with typical $\mathrm{H}$. pylori infection initially develop chronic active gastritis, in which $\mathrm{H}$. pylori organisms are observed in antrum, fundus, and corpus (usually more numerous in the antrum). As disease progresses, significant loss of gastric glands occur, known as gastric atrophy. ${ }^{9}$ Gastric atrophy results from the loss of gastric epithelial cells that are not replaced by appropriate cell proliferation or from the replacement of the epithelium by intestinal-type epithelium (intestinal metaplasia). Thus it is associated with the development of hypochlorhydria and decrease acid pepsin secretion. As disease progresses the numbers of $\mathrm{H}$. pylori detectable in the stomach decreases. ${ }^{9}$

In this study, the patients presented with gastric symptoms, anaemia and easy fatiguability. Serum vitamin $B_{12}$ deficiency was evaluated with endoscopy, histopathologic examination and test for $\mathrm{H}$. pylori. Study showed a high prevalence of chronic atrophic gastritis in patients with cobalamin deficiency $(54.1 \%)$ and $32.5 \%$ of them had evidence of chronic antral gastritis. Majority of them also showed evidence of $\mathrm{H}$. pylori infection on biopsy $(56.6 \%$, 68 patients). However in remaining cases of atrophic gastritis too, $\mathrm{H}$. pylori was implicated as the cause. Although direct evidence was not present, most of our patients were showing multifocal atrophic gastritis which is characteristic of $\mathrm{H}$. pylori which is in contrast to diffuse atrophic gastritis of pernicious anaemia.

Study conducted by Kaptan ${ }^{11}$ et al showed presence of $\mathrm{H}$. pylori in $56 \%$ of the 138 patients with Vitamin $\mathrm{B}_{12}$ deficiency, and eradication treatment for $\mathrm{H}$. pylori resulted in improvement of Vitamin B $_{12}$ level. Similarly in a study conducted by $\operatorname{Serin}^{12}$ et al showed significant improvement in serum Vitamin B $_{12}$ level and decrease in inflammation of antrum and corpus and decrease in neutrophil activation score after H. pylori eradication treatment. Shuval-Sudai and Granot ${ }^{13}$ investigated 133 patients in Israel and found out significant association of H.pylori infection and low prevalence of cobalamin and folate levels

The present study showed significant relationship between $\mathrm{H}$. pylori and biopsy finding, and between Vitamin $\mathrm{B}_{12}$ level and H.pylori, suggesting the possibility of H.pylori causing atrophic gastritis which in turn producing decreased cobalamin absorption and Vitamin $\mathrm{B}_{12}$ deficiency.

Study done by Yuksel et a $\mathrm{l}^{14}$ correlating mucosal biopsy with $\mathrm{H}$.pylori load concluded that $\mathrm{H}$. pylori in gastric mucosa influences Vitamin B ${ }_{12}$ level.

\section{LIMITATIONS}

Our study was done in $\mathrm{H}$. pylori endemic area and we have not assessed the prevalence of $\mathrm{H}$. pylori in general population. Similarly other causes of vitamin $\mathrm{B}_{12}$ deficiency were not completely ruled out. Study would have been better if improvement of vitamin $\mathrm{B}_{12}$ levels was assessed following $\mathrm{H}$. pylori eradication therapy which warrants the need of further follow up studies.

\section{CONCLUSION}

H. pylori has an effect on gastric mucosa, which influences the absorption of vitamin $\mathrm{B}_{12}$. Thus individuals with $\mathrm{B}_{12}$ deficiency must be subjected for diagnostic evaluation of H.pylori infection and appropriate therapy must be initiated.

\section{REFERENCES}

1. Dharmarajan TS and Norkus EP. Approaches to vitamin B12 deficiency: Early treatment may prevent devastating complications. Postgrad Med 2001; 110:99-106.

2. Carmal R. Malabsorption of cobalamine. Baillieres Clin Haematol. 1995;8639-655

3. Cave DR. Transmission and epidemiology of Helicobacter pylori. Am J Med. 1996; 100(suppl 5A)12S-18S.

4. Weck MN, Gao L and Brenner H. Helicobacter pylori infection and chronic atrophic gastritis: associations according to severity of disease. Epidemiology 2009; 20(4):569-574.

5. Kumar V, Abbas AK and Aster JC. Robbins and Cotran Pathologic Basis of Disease. $9^{\text {th }}$ ed. Philadelphia: Elsevier Saunders; 2015. p. 763.

6. Dholakia KR, Dharmarajan TS, Yadav D, Oiseth S, Norkus EP and Pitchumoni CS. Vitamin B12 deficiency and gastric histopathology in older patients. World J Gastroenterol 2005;11(45):7078-7083.

7. Baik HW and Russell RM. Vitamin B12 deficiency in the elderly. Annu Rev Nutr 1999; 19:357-377. 
8. Vogiatzoglou A, Smith AD, Nurk E, Berstad P, Drevon CA, Ueland PM, et al. Dietary sources of vitamin B-12 and their association with plasma vitamin B-12 concentrations in the general population: The Hordaland Homocysteine Study. Am J Clin Nutr 2009; 89:1078-1087.

9. Desai HG and Gupte PA. Helicobacter pylori link to pernicious anaemia. Assoc of Physicians of India 2007; 15:55(C):857.

10. Peterson $A M$ and Krogfelt KA. Helicobacter pylori an invading organism? A review. FEMS Immunol Med Microbiol 2003; 36:117-126.

11. Kaptan K, Beyan C, Ural AU, Cetin T, Avcu F, Gülşen M, et al. Helicobacter pylori- Is It a Novel Causative Agent in Vitamin B12 Deficiency. Arch Intern Med. 2000; 160(9):1349-1353.
12. Serin E, Gumurdulu Y, Ozer B, Kayaselcuk F, Yilmaz U and Kocak R. Impact of Helicobacter pylori on the development of vitamin B12 deficiency in the absence of gastric atrophy. Helicobacter 2002;7:337-341.

13. Akcam M, Ozdem S, Yilmaz A, Gultekin M and Artan R. Serum ferritin, vitamin B12, folate, and zinc levels in children infected with Helicobacter pylori. Digestive diseases and sciences 2007; 52(2):405-410.

14. Gumurdulu Y, Serin E, Ozer B, Kayaselcuk F, Kul K, Pata C, et al. Predictors of vitamin B 1 2 deficiency: Age and helicobacter pylori load of antral mucosa. Turkish journal of gastroenterology 2003;14(1):44-49.

\section{Authors Contribution:}

RK-Concept and design of the study, reviewed the literature, manuscript preparation and critical revision of the manuscript; JJ-Conceptualized study, literature search, statistically analyzed and interpreted, prepared first draft of manuscript and critical revision of the manuscript; DMT-Concept, collected data and review

of literature and helped in preparing first draft of manuscript.

\section{Orcid ID:}

Dr. Ravi K:(D) http://orcid.org/0000-0003-3043-1955

Dr. Jacob Joseph: http://orcid.org/0000-0002-9794-3982

Dr. David Mathew Thomas: http://orcid.org/0000-0003-2325-1614

Source of Support: None. Conflict of interest: None declared. 